was injected into the stomachs of the mice and was presumably absorbed and may have produced its effect after it was secreted in the urine. This fluorene derivative appears to be suitable for studies of anticarcinogenic or neutralizing agents; but its carcinogenic action is less easily modified by dietetic changes than is the action of the azo compounds such as dimethylaminoazobenzene.

One of the simplest carcinogenic agents is urethane or ethylcarbamate. American workers first found that this compound induced tumours of the lung in mice, and the same result has now been obtained in Britain. When one considers that urethane was used as an anæsthetic and that acetylaminofluorene was introduced as an insecticide, it might seem desirable that all new chemotherapeutic agents should be tested for carcinogenic action before they are widely used in medicine.

Experiments on the antagonism to the carcinogenic action of benzpyrene carried out by Dr. F. Dickens and Dr. H. Weil Malherbe at Newcastle have revealed something of the nature of the anticarcinogenic material present in mouse fat. The action of the fat appears to be due to unsaturated fatty acid derivatives. The most active anticarcinogenic material was present in the phosphatide fraction, and phosphatides inhibit both carcinogenic action and benzpyrene excretion. Cholesterol increases the rate of excretion of benzpyrene and accelerates the production of tumours. The results suggest that metabolism of the hydrocarbon is necessary for carcinogenesis, and that the true or ultimate carcinogen may be a metabolite. The same investigators have studied the remarkable solvent action of aqueous solutions of purines on polycyclic hydrocarbons. The solvent power of purines increases with the number of carbonyl groups and with the number of $\mathrm{N}$-methyl groups in the purine molecule; hypoxanthine with no methyl or carbonyl groups has very little solvent action, but tetramethyl uric acid is a very good solvent for 3 : 4-benzpyrene. Nucleosides and nucleotides have some solvent action but less than that of the corresponding unsubstituted aminopurines.

Work at the Mount Vernon Hospital has thrown light on the relationship of mitosis and carcinogenic action. Thus croton oil, which has a cocarcinogenic effect, induces hyperplasia of the skin, and cantharidin inhibits both mitosis of epidermal cells and the carcinogenic action of benzpyrene. The same workers have shown by fluorescence spectrography that benzpyrene applied to the skin of mice is absorbed in about four hours and disappears within twenty-four hours following a single painting. The specific carcinogenic action of benzpyrene therefore probably occurs within a fow hours of application to the skin. Mice were painted with benzpyrene on one flank at midday and on the other flank at midnight. The midnight paintings induced more tumours than did the midday applications. With midnight applications the benzpyrene content of the tissue would be highest during the day when mitosis is most frequent. The evidence obtained indicates that the process of carcinogenesis by benzpyrene occurs while cells are dividing. This is in agreement with the fact that hyperplasia and carcinogenesis are often interdependent.

The results obtained in Newcastle and at the Mount Vernon Hospital taken together suggest that the actual carcinogenic process may involve the action of a metabolic product of a carcinogen on some cell constituent during the process of mitosis.
By investigating statistics of mortality from cancer, Prof. and Mrs. E. L. Kennaway have been able to show that though the incidence of cancer of the scrotum is very much higher among chimney-sweeps than among the general population, the mean age of death from this cause is about the same in the two classes. This is an example of an external factor which increases the incidence of cancer among the population yet has no effect upon the incubation period. A similar effect is shown in the incidence of lung cancer in chromate workers in Germany. There appears to be some mechanism resisting any acceleration in the development of cancer. The fact that types of cancer which tend to be inherited show differences in age of incidence in susceptible families and in the general population suggests that the resistance has a genetical basis.

In addition to work on carcinogenesis, experiments have been carried out on the chemotherapy of cancer, on the relation of viruses to cancer and carcinogens and on the immunity to subsequent tumours which develops when animals bearing tumours are suitably irradiated with $X$-rays. The report includes accounts of treatment of cancer in several hospitals by irradiation and surgery. The Clinical Cancer Research Committee presents a detailed analysis of the data from more than five hundred cases of cancer of the pharynx and larynx.

E. BOYland.

\section{INTERNATIONAL ASTRONOMICAL UNION}

TN order to set the wheels of international co-operation in astronomy turning smoothly again after the gap necessarily caused in many cases by the war years, the Executive Committee of the International Astronomical Union recently called together as an advisory body representatives from the United States of America and from a number of European countries. At a meeting which took place during March 7-13, in the rooms of the Danish Academy of Sciences, Copenhagen, the following countries were represented: Belgium, Czechoslovakia, Denmark, France, Great Britain, Netherlands, Norway, Poland, Sweden, Switzerland, U.S.A., U.S.S.R. and the Vatican City State. The British representa. tives were the Astronomer Royal, Prof. W. M. H. Greaves and Prof. F. J. M. Stratton. After a welcome from Prof. Elis Strömgren on behalf of the Danish National Committee of Astronomy and from Prof. Niels Bohr on behalf of the Danish Academy, the meeting settled down to business under the presidency of Sir Harold Spencer Jones, with the guidance of the general secretary, Prof. J. H. Oort, director of the Leyden Observatory.

Committees were appointed to advise the Executive Committee on Publications on Solar Phenomena, on Variable Stars (names, catalogues and ephemerides), on Bibliography, on Fundamental Astronomy and Minor Planets and on Exchanges between Astron. omers of different Countries. Annual grants were recommended in connexion with the above and for certain institutions for which the Union has been partly responsible in past years. Among other projects which were discussed favourably, mention may be made of an International Observatory, for which it was realized that the backing of the United Nations Educational, Scientific and Cultural Organ- 
isation might have to be secured. The various standing commissions of the Union appointed in 1938 were revised to meet the changes of the past eight years.

Public lectures were given by Prof. H. Shapley on the galaxies and by Sir Harold Spencer Jones on Halley and his times. A colloquium on interstellar material was held in which the following took part : B. Strömgren, ter Haar, Struve, Oort, Minnaert, Stebbins, Lindblad, Shapley and (by proxy) Swings. The meeting was thoroughly successful in gaining its main objectives. It was found impossible to fix the date and place of the next general assembly of the Union, but there were indications that it could not take place before 1948.

F. J. M. S.

\section{ANTIBACTERIAL SUBSTANCES PRODUCED BY BACTERIA AND FUNGI}

$\mathrm{O}$ UR knowledge of the effects of antibacterial substances produced by or derived from bacteria or fungi continues to increase. A new antibacterial substance named 'bacitracin' has been described by B. A. Johnson, H. Anker and F. L. Meleney (Science, 102, 376,1945 ; and see the Lancet, 641, Nov. 17, 1945). It is produced by a Gram-positive aerobic sporing rod, and the crude brew obtained inhibited a hæmolytic streptococcus when it was diluted $1: 2,000$ to $1: 10,000$. Some of the most susceptible organisms were $\beta$-hæmolytic streptococcus, pneumococcus, some clostridia, anaerobic staphylococci and some strains of anaerobic streptococci. Gram-negative organisms were not sensitive to it. 'Bacitracin' is soluble in water and butanol, unstable to alkali, stable to acid and to heating to $100^{\circ} \mathrm{C}$. for fifteen minutes. Impure extracts were not toxic to animals and did not irritate the conjunctiva. A single intraperitoneal injection of it ensured the survival of 80 per cent of mice infected via the peritoneal cavity with a streptococcus, but 30-40 per cent also survived after a single subcutaneous injection and 80-90 per cent after subcutaneous injections repeated every three hours. Subcutaneous injections repeated every three hours ensured the survival of 80 per cent of guinea pigs infected with the gas-gangrene organisms, Clostridium welchii and $C$. septicum. It is claimed that local treatment of human infections caused by susceptible organisms are comparable to those of penicillin.

The properties of mycophenolic acid, which is one of the metabolic products of Penicillium brevi. compactum, have been described by Sir Howard Florey and his collaborators at Oxford (Lancet, 46, Jan. 12, 1946). Mycophenolic acid is said to be the first antibiotic produced by a mould which has been crystallized. This was done by Gosio in 1896, who obtained it from media on which Penicillium glaucum was growing. Mycophenolic acid seldom reaches titres of the order of 1 in 100,000 or more and is more active against Gram-positive than against Gram-negative organisms, but its activity is more markedly affected than is that of other antibacterial substances by the size of the inoculum used. It inhibited Staphylococcus aureus, Streptococcus pyogenes and $C$. diphtherioe, but did not inhibit Bact. coli or Salmonella typhi. It inhibits in vitro the growth of many strains of fungi pathogenic to man and plants at titres up to 1 in
80,000 , but apparently even strong solutions of it cannot kill these under experimental co nditions.

In the same issue of the Lancet (p. 44) Dr. A. G. Sanders, another Oxford worker, discusses the effects of the antibiotics mycophenolic acid, aspergillic acid, proactinomycin, cheiroline, claviformin, gliotoxin, helvolic acid, penicillic acid and penicillin upon fungi pathogenic to man, and concludes that claviformin and gliotoxin have a powerful action upon them. Gliotoxin is, however, unstable under certain conditions. Further investigation of aspergillic acid and cheiroline might, Dr. Sanders concludes, produce useful results.

G. LAPAGE.

\section{VISCOSITY OF LIQUIDS AND COLLOIDAL SOLUTIONS}

$\mathrm{T}$ HE third volume of the proceedings in Russian of the conference arranged by the U.S.S.R. Academy of Sciences on the viscosity of liquids and colloidal solutions, held in Moscow in 1941, has now reached Great Britain (Moscow and Leningrad: Academy of Sciences)*. The volume is sub-titled "Supplementary Reports and Articles from the Section on 'The Viscosity of Molten Materials at High Temperatures" ". There are ten original papers and a general discussion on some of these, and on the contributions from the same section published in the earlier volumes.

Of these papers, two are concerned with metals : Polyak and Serge'ev describe an oscillating ball viscometer for aluminium and its alloys, for which metals they also use a capillary viscometer; and Shvidkovskir, Alkhmetzyanov, Belyankin and Shush. panov give viscosity-temperature $(n / t)$ curves obtained with a rotation viscometer for steel.

Markovskir discusses the effects of small quantities of $\mathrm{MgO}, \mathrm{Al}_{2} \mathrm{O}_{3}, \mathrm{SiO}_{2}$, etc., on $\gamma_{1} / t$ curves for molten calcium carbide, and the remaining seven papers deal with slags and glasses, mostly relating chemical composition to $\eta / t$ curves. Sokol'skil uses the $\log$ $\log n / t$ plot, Okhotin gives an empirical formula relating equiviscous temperature to the composition of glasses, and Leiba and Komar' extend their work on slags, published in Volume 1. There is also a further contribution by Leont'eva, who gets good linear relations between crystallization speeds and fluidity of glasses.

Perhaps the most interesting paper is that of Yevstrop'ev, who discusses the viscosity-temperature coefficient of glasses and other molten systems, comparing the usual well-known equations relating $\eta$ to temperature. With some glasses and certain salts (for example, sodium chloride and silver nitrate), a plot of $\log \eta$ against the reciprocal of the square of the temperature (as proposed by the author in an earlier paper) gives a better straight line than a plot against the reciprocal of temperature itself; but in other cases neither plot appears to be very satisfactory.

It is most unfortunate that, as an inevitable result of the War, the publication of these reports has had to be so long delayed. Perhaps one may dare to hope that the findings of the conference, brought up to date in some suitable form, may before long be made available in English. G. W. Scotr BLArr.

*The first and second volumes were reviewed in Nature, 156, 147 (1945). 